\title{
RIESGO ECOLÓGICO POTENCIAL POR ARSÉNICO EN LA DESEMBOCADURA DEL RÍO LOA, NORTE DE CHILE
}

\author{
Ecological potential risk by arsenic in the Loas's river mouth, north of Chile
}

Venecia HERRERA ${ }^{1,2,3 *}$, Cristian CARRASCO ${ }^{1,2}$, Paola ARANEDA $^{2}$, Viviana VARAS $^{3}$ y Cynthia ROJO ${ }^{2}$

${ }^{1}$ Laboratorio de Química Analítica y Ambiental, Facultad de Ciencias de la Salud, Universidad Arturo Prat, Av. Arturo Prat 2120, Iquique, Chile, Código Postal 1000100

${ }^{2}$ Centro de Investigación del Medio Ambiente, Universidad Arturo Prat, Casilla 121, Iquique, Chile, 1000100

${ }^{3}$ Centro de Investigación y Desarrollo en Recursos Hídricos, Universidad Arturo Prat, Vivar 493, oficina 201, Iquique, Chile, Código Postal 1000100

*Autora para correspondencia: vherrera@unap.cl

(Recibido enero 2018; aceptado octubre 2018)

Palabras clave: humedal, biodisponibilidad, extracción secuencial, código de evaluación de riesgo, efectos de rango bajo y medio

\section{RESUMEN}

En el río, laguna y zona de mezcla del río Loa (norte de Chile), así como en las playas aledañas a su desembocadura, se determinó el riesgo ecológico potencial por arsénico en las fracciones disponibles del sedimento, con base en los efectos de rango bajo y medio. Se dedujeron la constante de distribución, el índice de geoacumulación (Igeo) y el factor de enriquecimiento (FE) de As. Para estimar el As reactivo se compararon tres procedimientos de extracción simple, y con el fin de obtener el código de evaluación de riesgo se aplicaron las dos primeras etapas de la extracción secuencial de Tessier y la biodisponibilidad según el esquema BCR modificado. Las aguas continentales saladas y alcalinas presentaron un carácter reductor, bajos contenidos de $\mathrm{OD}, \mathrm{N} / \mathrm{P}$ y $\mathrm{Cu}$, pero As elevado (1.13-1.80 mg/L), diluido en el mar a $0.012 \mathrm{mg} / \mathrm{L}$. Los sedimentos continentales neutros presentaron materia orgánica baja (2-6\%), niveles aceptables de N/P, $\mathrm{CaCO}_{3}$ (5.3-31\%) y Cu, pero As elevado (516-856 mg/kg). En sedimentos marinos alcanzó 20 $\mathrm{mg} / \mathrm{kg}$ de As. Los valores del Igeo establecen la categoría de contaminación terrestre, pero no marina, aunque los FE confirman la presencia de riesgo potencial elevado en la desembocadura. Las extracciones simples y el código de evaluación de riesgo lo señalan como móvil y biodisponible. El nivel de As en el sedimento fluvial asociado a las fracciones intercambiable, reducible y oxidable, confirman riesgo potencial para el ecosistema en condiciones alcalinas y reductoras. En cambio, en el borde costero, el As se encuentra asociado mayoritariamente a las fracciones residual e intercambiable, lo cual reduce el riesgo potencial.

Key words: wetland, bioavailability, sequential extraction, risk assessment code, low and medium range effect

\begin{abstract}
Potential ecological risk by arsenic in the available fractions of the sediment in the river, lagoon, mixing zone and beaches bordering the mouth of the Loa River, north
\end{abstract}


of Chile, was determined based on low and medium range effects. The distribution constant, geoaccumulation index and As enrichment factor were deduced. To estimate reactive As, three simple extraction procedures were compared. In order to obtain the risk assessment code, the first two stages of sequential Tessier extraction and bioavailability were applied according to the modified BCR schema. The salty and alkaline continental waters showed a reducing character, low $\mathrm{OD}, \mathrm{N} / \mathrm{P}$ and $\mathrm{Cu}$, but high As $(1.13-1.80 \mathrm{mg} / \mathrm{l})$, diluted in the sea at $0.012 \mathrm{mg} / \mathrm{L}$. The neutral continental sediments presented low organic matter (2-6\%), acceptable levels of N/P, $\mathrm{CaCO}_{3}(5.3-31 \%)$ and $\mathrm{Cu}$, but elevated As (516-856 mg/kg). As reached levels of $20 \mathrm{mg} / \mathrm{kg}$ in marine sediments. According to the geoaccumulation index values, there was terrestrial but not marine pollution, although the enrichment factors confirm the presence of high potential risk at the river mouth. Simple extractions and the risk assessment code point to As as mobile and bioavailable. The level of As in the fluvial sediment associated with interchangeable, reducible and oxidizable fractions confirm potential risk for the ecosystem under alkaline and reducing conditions. On the other hand, in the coastal border As was found associated mainly with residual and interchangeable fractions, which reduces this potential risk.

\section{INTRODUCCIÓN}

El Arsénico (As) se encuentra distribuido en suelos, sedimentos, aguas, aire y organismos (Mandal y Suzuki 2002). Su concentración natural en cuencas del norte de Chile depende de la hidrología y mineralogía, entre otras propiedades, y los ríos que nacen en la Cordillera de los Andes lo transportan hacia la parte baja de éstas (Bundschuh et al. 2012). Los humedales costeros (zonas de transición entre agua continental y de mar) son el hábitat de especies migratorias y residentes y permiten su alimentación (Figueroa et al. 2009, Sielfeld et al. 2012). Cuando se modifican las condiciones ambientales de estos sistemas, tales como $\mathrm{pH}$ ácido-base, potencial redox $\left(\mathrm{E}_{\mathrm{h}}\right)$, salinidad y materia orgánica, las especies químicas de As asociadas a los sedimentos, pueden ser redisueltas en el agua causando una contaminación secundaria (Smedley y Kinniburgh 2002, Fang y Chen 2015). Se considera que el As inorgánico es dañino para las células y nocivo para la biota, ya que inhibe la fotosíntesis, el crecimiento y la reproducción de especies (WHO 2001), amenazando la calidad de los ecosistemas acuáticos por su capacidad para transferirse a las cadenas tróficas (Smedley y Kinniburgh 2002, Pell et al. 2013, Wang et al. 2016). Las especies de As inorgánico, presente en las aguas, son extremadamente tóxicas, mientras que los compuestos de As orgánico son menos perjudiciales para la salud. Los primeros síntomas de exposición prolongada a As inorgánico en agua o alimentos se observan en la piel (Mandal y Susuki 2002).

El estándar de calidad de As para sedimentos en ambiente marino (sediment quality guidelines, $\mathrm{SQG}_{\mathrm{s}}$ ) establece, según el método de su efecto de rango bajo (effect range low, ERL), una concentración admisible de $8.2 \mathrm{mg} / \mathrm{kg}$, y por su efecto de rango medio (effect range medium, ERM) un máximo de $70 \mathrm{mg} /$ $\mathrm{kg}$ (Fang y Chen 2015, Cagnin et al. 2017, Han et al. 2017). Para establecer categorías de contaminación en ecosistemas acuáticos se ha utilizado el índice de geoacumulación (Igeo), con el fin de categorizar el grado de contaminación de los sedimentos desde no contaminado hasta fuertemente contaminado (en escala 0-4) (Han et al. 2017). Asimismo, para estimar el riesgo ambiental y distinguir entre origen natural o antrópico de los sedimentos marinos en superficie se determina el factor de enriquecimiento (enrichment factor, EF), que puede alcanzar un grado de enriquecimiento extremadamente severo. Este indicador relaciona las concentraciones del contaminante referido con otro elemento traza normalizador asociado a la litología ( $\mathrm{Al}, \mathrm{Fe}, \mathrm{Cu}$ ) en la muestra y su basal (Cagnin et al. 2017).

Sin embargo, la estimación del riesgo ecológico potencial y biológico en un ecosistema se determina según la disponibilidad del elemento traza en el medio o bien por su grado de asociación a componentes de la matriz del sedimento, y no sólo por su concentración total. Para los sedimentos se han sugerido protocolos de extracción (Tessier et al. 1979, Ure et al. 1993, Arain et al. 2008, Chen et al. 2014). El procedimiento de extracción secuencial más ampliamente usado en sedimentos contaminados fue propuesto por Tessier et al. (1979), según el cual las dos primeras extracciones estiman el código de evaluación de riesgo (risk assessment code, RAC) en el ambiente acuático marino (Wang et al. 2016). A fin 
de homogeneizar resultados de fraccionamiento de elementos traza, la Community Bureau of Reference (BCR) sugirió una extracción secuencial en cuatro etapas (Ure et al. 1993). Arain et al. (2008) modificaron el protocolo BCR para disminuir tiempo en el análisis usando ultrasonido en la digestión y definiendo la etapa 1 como índice de la biodisponibidad para organismos acuáticos.

Es sabido que el As se presenta en concentraciones altas en el ambiente de la cuenca del río Loa, al norte de Chile. Su origen se ha relacionado con el volcanismo y el geotermalismo asociados a la cuenca, y en las últimas décadas se ha vinculado con actividades de la minería del cobre en Chuquicamata, que forman parte del proyecto minero de refinería más importante de la zona (Romero et al. 2003, DGA 2005, Pell et al. 2013, Bugueño et al. 2014). El cauce angosto del río Loas, con una longitud de $440 \mathrm{~km}$, es un corredor biológico que atraviesa parte del desierto de Atacama, transportando sustancias disueltas que lo clasifican como un río salado. En el desierto costero logra mantener un flujo de descarga hacia el mar, desembocando en el océano Pacífico (caleta Huelén), sector costero del norte de Chile con importante productividad primaria (Herrera y Escribano 2006). En la desembocadura es cruzado por la ruta $\mathrm{A} 1$, que une las ciudades de Iquique y Antofagasta por la costa. Unos $300 \mathrm{~m}$ antes de descargar al mar, el río forma un humedal característico en forma de lagunas someras que genera el hábitat propicio para aves nativas y migratorias, así como flora y fauna adaptada en la quebrada del cauce final del río. Debido a que no hay información científica suficiente y por las condiciones geomorfológicas y la batimetría del humedal en la desembocadura, en cuatro de los ambientes (cauce del río, laguna, zona de mezcla y playas aledañas al norte y sur) se determinó la presencia de riesgo ecológico potencial debido a las fracciones disponibles de As en sedimentos, las cuales pueden movilizarse o ser absorbidas por organismos de acuerdo con los ERL y ERM referidos a sus SQGs, previa evaluación de las propiedades físicas y quúimicas. Se dedujeron los valores de la constante de distribución, el Igeo y el FE con referencia a $\mathrm{Cu}$. Debido a la presencia de piedra caliza en el sedimento del humedal y para estimar el porcentaje de As reactivo, se aplicaron tres procedimientos de extracción simple: $\mathrm{HCl} 1 \mathrm{M}$, $\mathrm{H}_{2} \mathrm{SO}_{4} 0.25 \mathrm{M}$ y amortiguador de acetato $1 \mathrm{M} \mathrm{pH}$ 5.0. Para establecer el estado de los ecosistemas, el RAC y la biodisponibilidad, se aplicaron las dos primeras etapas de la extracción secuencial de Tessier et al. (1978) y el esquema BCR en cuatro etapas modificado por Arain et al. (2008).

\section{MATERIALES Y MÉTODOS}

\section{Área de estudio y toma de muestras}

La gran cuenca exorreica $\left(33570 \mathrm{~km}^{2}\right)$ del río Loa $\left(21^{\circ} 00^{\prime}-22^{\circ} 58^{\prime} \mathrm{S}\right.$; $\left.70^{\circ} 05^{\prime} 68^{\circ} 00^{\prime} \mathrm{O}\right)$ de Tarapacá y Antofagasta al norte de Chile, posee distintas hoyas o cursos de agua que conforman la cuenca de régimen pluvial. Sus principales tributarios en el altiplano son el río Salado y el río San Salvador. La cuenca del salar de Llamara (1100 msnm), que está conectada hidrológicamente al sur con el río Amarga y su quebrada, es afluente del cauce final del río Loa (Lictevout et al. 2013). En la desembocadura hay un clima desértico costero caracterizado por abundantes nieblas matinales producto de la corriente fría de Humboldt. La evaporación desempeña un rol predominante en el balance hídrico d esta zona, ya que supera ampliamente las escasas a nulas precipitaciones al alcanzar valores de 2000 a $3000 \mathrm{~mm} /$ año (DGA 2005, Lictevout et al. 2013). La confluencia del agua de la Cordillera de la Costa hacia el mar ha permitido el desarrollo de distintas especies de flora que dan forma a una quebrada con un cauce angosto-somero de aproximadamente 600 $\mathrm{m}$, que antes de desaguar al mar forma un humedal caracterizado por dos lagunas someras (una de ellas permanente). Las características del sector permiten el desarrollo de vegetación acuática y la presencia de fauna amenazada y en peligro (Guerra 2005, Sielfeld et al. 2012).

Las campañas de muestreo se realizaron en noviembre de 2015. Se tomaron muestras de sedimentos y aguas en nueve sitios desde la zona de apertura de la Cordillera de la Costa hasta su desembocadura en el océano Pacífico (Fig. 1). El diseño de muestreo consideró tres sitios en el cauce final del río (R1, R2 y R3), sistema lótico de aproximadamente $500 \mathrm{~m}$ de largo hasta el puente de la ruta A1; tres sitios en la laguna somera permanente (L4, L5 y L6), un sistema léntico pero con hidrodinámica superficial del desagüe del río, y un sitio en la zona de mezcla (ZM7) de la plataforma litoral que forma el humedal costero $\left(4200 \mathrm{~m}^{2}\right)$ a $1.5 \mathrm{msnm}$. Los cuerpos de agua son muy someros (20-40 cm de profundidad) y por sus propiedades biológicas, químicas y físicas dan cuenta de un humedal estuarino (Guerra 2005). En la bahía de la costa, arenosa y rocosa, se seleccionó un sitio (PN8) en la parte norte, caracterizada por una playa de arena con alta pendiente y fuerte oleaje, y otro (PN9) en el sector de la costa sur, caracterizada por una zona de cantos rodados de intermareal rocoso. Las muestras de agua se recolectaron en envases de polietileno y las del sedimento superficial $(0-10 \mathrm{~cm})$, de 


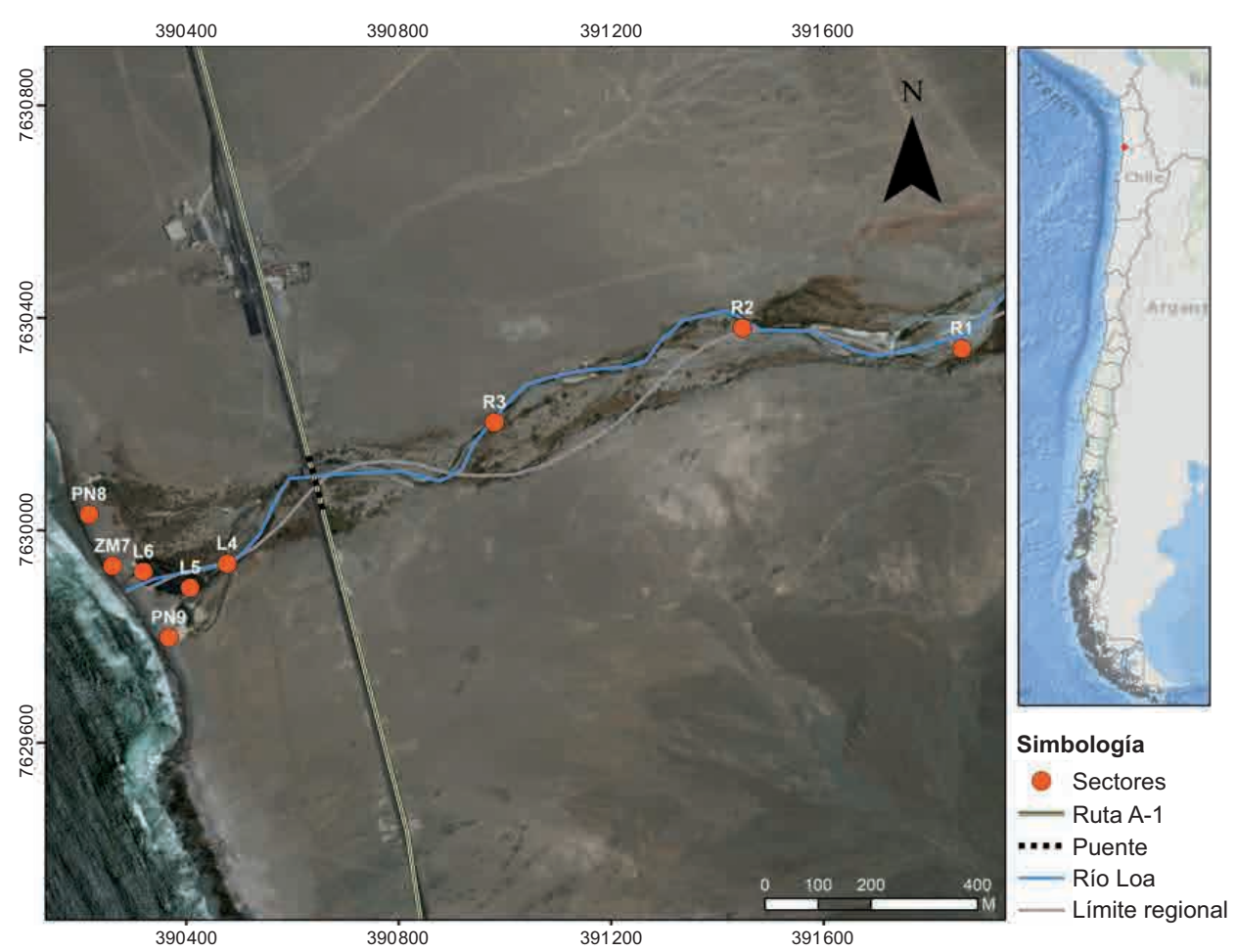

Fig. 1. Mapa de la desembocadura del río Loa. Ubicación y simbología en los sitios del cauce final del río, la laguna, zona de mezcla y playas de los sectores norte y sur de la desembocadura

aproximadamente $2 \mathrm{~kg}$, se tomaron con un core de PVC y se transfirieron a bolsas plásticas herméticamente selladas. En cada sitio se recolectaron tres réplicas de las muestras.

\section{Parámetros físicos y químicos de aguas y sedi- mentos}

En las campañas de muestreo se midieron la conductividad eléctrica (CE), el $\mathrm{pH}$, el potencial redox en milivolts $\left(\mathrm{E}_{\mathrm{h}}\right)$ y el oxígeno disuelto $(\mathrm{OD})$ con un equipo WTW multiline P3. Los análisis de agua se realizaron por duplicado siguiendo los protocolos estandarizados por la APHA (1992). En las muestras filtradas a $0.45 \mu \mathrm{m}$, se determinó la presencia de nitrato $\left(\mathrm{N}^{-\mathrm{NO}_{3}}{ }^{-}\right)$mediante espectroscopia UV a $220 \mathrm{~nm}$ y fosfato $\left(\mathrm{P}_{-} \mathrm{PO}_{4}{ }^{-3}\right)$ por el método del ácido ascórbico en espectrofotómetro Pekín Elmer Labda 25. Las muestras de sedimentos se secaron a temperatura ambiental $\left(24 \pm 1^{\circ} \mathrm{C}\right)$, se tamizaron a 2 $\mathrm{mm}$ y se almacenaron en desecadora. Las medidas de $\mathrm{pH}$ y $\mathrm{CE}$ se obtuvieron en extractos acuosos en una proporción 1:3. La mezcla se agitó mecánicamente durante $2 \mathrm{~h}$ y en el filtrado se determinaron el $\mathrm{pH}$ y la conductividad eléctrica con instrumentos de sobremesa Hanna HI 9126 y Orion 3 Start
Conductivity Benchtop, respectivamente. La determinación de carbono orgánico fácilmente oxidable (COFO) se realizó por volumetría redox con dicromato de potasio $\left(\mathrm{K}_{2} \mathrm{Cr}_{2} \mathrm{O}_{7} 1 \mathrm{~N}\right)$, el indicador ácido difenilaminosulfonato de bario y sulfato ferroso $\left(\mathrm{FeSO}_{4} 0.5 \mathrm{~N}\right)$, previamente estandarizado. Para extraer nitrato desde los sedimentos, se saturaron $50 \mathrm{~g}$ de muestra con $50 \mathrm{~mL}$ de solución de cloruro de potasio $(\mathrm{KCl} 2 \mathrm{M})$ y agitación mecánica a 150 rpm por $1 \mathrm{~h}$. Para el análisis de fosfato disponible se aplicó el método de Olssen: se saturaron $50 \mathrm{~g}$ de sedimento con $50 \mathrm{~mL}$ de solución de bicarbonato de sodio $\left(\mathrm{NaHCO}_{3} 0.5 \mathrm{M} \mathrm{a} \mathrm{pH} 8.5\right)$, agitando por $30 \mathrm{~min}$. La determinación de carbonato de calcio $\left(\mathrm{CaCO}_{3}\right)$ se hizo por volumetría ácido-base con ácido perclórico $\left(\mathrm{HClO}_{4} 1 \mathrm{~N}\right)$; posteriormente se valoró la solución con hidróxido de sodio $(\mathrm{NaOH} 0.5 \mathrm{~N})$, y el $\mathrm{pH}$ se registró con peachímetro de sobremesa (Sadzawka et al. 2006).

\section{Análisis de arsénico y cobre}

Alícuotas de muestras de agua filtrada por membrana Merck a $<0.45 \mu$ m fueron digeridas con $\mathrm{HNO}_{3} 10 \%$ (suprapure [sp] Merck) en un sistema semicerrado para la cuantificación de elementos tra- 
za. La digestión de sedimentos continentales siguió la metodología descrita por Herrera et al. (2009): se tamizaron en malla de $63 \mu \mathrm{m}$ y se usaron procesos digestivos en bombas de teflón a alta presión con la mezcla $\mathrm{HCl}$ (sp Merck) y $\mathrm{HNO}_{3}$ (3:1) en sistema abierto por $16 \mathrm{~h}$ a $20{ }^{\circ} \mathrm{C}$, luego por $5 \mathrm{~h}$ a $50{ }^{\circ} \mathrm{C}$ y posteriormente, cerradas herméticamente, por $3 \mathrm{~h}$ a $170^{\circ} \mathrm{C}$. Los extractos se mantuvieron en envases de polietileno y se refrigeraron a $4{ }^{\circ} \mathrm{C}$. Las digestiones de los sedimentos de ambientes marinos costeros se llevaron a cabo mediante la misma metodología, salvo por la adición de $6.5 \mathrm{ml}$ de ácido fluorhídrico concentrado (sp Merck) y ácido bórico (PA Merck). Este mismo tratamiento se aplicó al material de referencia certificado y blanco de reactivos.

La determinación de As total se llevó a cabo por espectroscopia de absorción atómica en la modalidad de generación de hidruro (EAA-GH), en un equipo Perkin Elmer modelo PinAAcle $900 \mathrm{H}$ con generador de hidruros FIAS 100, previa reducción desde As (V) a As (III), con KI en medio de ácido ascórbico y $\mathrm{HCl}$ concentrado. La curva de calibración se preparó desde una solución Tritrisol 1000 mg/L (Merck). Se midió a $193.87 \mathrm{~nm}$, en celda $\mathrm{T}$ de cuarzo a $900^{\circ} \mathrm{C}$, con llama de aire-acetileno (20 y 70-80 psi, respectivamente) y argón (50-100 psi). Los reactivos reductores fueron borohidruro de sodio PA Merck $\mathrm{NaBH}_{4} 0.2$ $\%$ en $\mathrm{NaOH} 0.3 \%$ ) a $6 \mathrm{~mL} / \mathrm{min}$ y solución ácida de $\mathrm{HCl} 10 \%$ a flujo de $10 \mathrm{~mL} / \mathrm{min}$.

Las concentraciones de $\mathrm{Cu}$ se determinaron por espectroscopia de absorción atómica en la modalidad de llama (aire-acetileno) a $324.7 \mathrm{~nm}$. Los análisis se hicieron por duplicado y la calidad de los resultados y validación de protocolos para sedimentos se evaluó mediante el material de referencia certificado Estuarine Sediment (SRM 1646) del National Bureau of Standards, el cual certifica $\mathrm{Cu}$ y As $(18 \pm 3$ y 11.6 $\mathrm{mg} / \mathrm{kg}$, respectivamente). Todas las concentraciones se expresan en peso seco de la muestra de sedimento.

Las determinaciones de la constante de distribución $\left(\mathrm{K}_{\mathrm{D}}\right)$ entre matrices, el índice de geoacumulación y el factor de enriquecimiento para As en los cuatro ambientes se calcularon según las siguientes ecuaciones:

$$
\begin{aligned}
& K D=\frac{[\text { As }] \text { sedimento }}{[\text { As]agua }} \\
& \text { lgeo }=\ln \frac{[\text { As }] \text { muestra }}{1.5 x[\text { As }] \text { base }} \\
& E F=\frac{([\text { As }] /[\text { metal de referencia }]) \text { muestra }}{([\text { As }] /[\text { metal de referencia }]) \text { base }}
\end{aligned}
$$

Debido a que no hay información científica disponible para el cálculo del Igeo y el EF, para el sedimento continental se consideró la concentración base de As reportada por Mandal y Suzuki (2002) de $20 \mathrm{mg} / \mathrm{kg}$, máximo valor encontrado en roca sedimentaria carbonatada, y para el sedimento marino el valor $8.2 \mathrm{mg} / \mathrm{kg}$ (ERL del SQGs), aunque Bowen (1979) estableció en sedimentos de arcillas marinas $13 \mathrm{mg} / \mathrm{kg}$ y un promedio natural de $7.7 \mathrm{mg} / \mathrm{kg}$. Para el cálculo del EF se usó $\mathrm{Cu}$ como metal normalizador y su concentración base de $34 \mathrm{mg} / \mathrm{kg}$, según el valor ERL del SQG (Han et al. 2017). Bowen (1979) señala un valor de $25 \mathrm{mg} / \mathrm{kg}$ para la concentración natural de $\mathrm{Cu}$ en sedimentos de arcilla marinas, $30 \mathrm{mg} / \mathrm{kg}$ en carbonatos marinos, $5.5 \mathrm{mg} / \mathrm{kg}$ en sedimento calizo, $30 \mathrm{mg} / \mathrm{kg}$ en arenoso y un promedio general de 33 $\mathrm{mg} / \mathrm{kg}$ del metal, coincidente con el valor usado basal de este estudio.

\section{Extracciones simples y secuenciales}

En los procedimientos de extracciones simple aplicados se usaron soluciones de ácido clorhídrico sp $1 \mathrm{M}$, ácido sulfúrico sp $0.25 \mathrm{M}$ y amortiguador de acetato $\mathrm{NaOAc} / \mathrm{HOAc} 1 \mathrm{M} \mathrm{pH} 5.0$ en las mismas condiciones operativas: alícuotas de 0.8-1.0 ( $\pm 0.0001 \mathrm{~g})$ $\mathrm{g}$ de sedimento $<63 \mu \mathrm{m}$, fueron puesto en contacto con el volumen del reactivo extractante $(25 \mathrm{~mL})$ y el sistema semiabierto fue agitado a $150 \mathrm{rpm}$ por $16 \mathrm{~h}$. Los extractos fueron filtrados y centrifugados, y el sobrenadante conservado en frascos de polietileno a $4{ }^{\circ} \mathrm{C}$.

Para obtener el valor del porcentaje del RAC se desarrollaron las dos primeras etapas del procedimiento de extracción secuencial de Tessier et al. (1979): alícuotas de 0.5-0.8 ( \pm 0.0001) g de sedimento $<63 \mu \mathrm{m}$, son tratadas con solución de cloruro de magnesio PA ( $\left.\mathrm{MgCl}_{2} 1 \mathrm{M} \mathrm{pH} 7.0\right)$, agitadas, filtradas $\mathrm{y}$ centrifugadas. El residuo fue puesto en contacto con amortiguador de acetato $\mathrm{NaOAc} / \mathrm{HOAc} 1 \mathrm{M} \mathrm{pH} 5.0$ en sistema semi abierto. Los sobrenadantes fueron conservados en frascos de polietileno a $4{ }^{\circ} \mathrm{C}$ hasta su cuantificación.

La extracción secuencial del protocolo modificado de BCR, incluido en el trabajo comparativo de Arain et al. (2008), fue aplicado a las muestras $<63 \mu \mathrm{m}$ en una extracción simple con ácido acético, HOAc $0.11 \mathrm{M}$ (fracción fácilmente intercambiable), y una secuencial en dos pasos con hidroxilamina, $\mathrm{NH}_{2} \mathrm{O}-$ $\mathrm{HHCl} 0.5 \mathrm{M} \mathrm{pH} 1.5$ (fracción reducible) y posterior tratamiento del residuo con una doble extracción con solución de $\mathrm{H}_{2} \mathrm{O}_{2}$ s.p. $8.8 \mathrm{M}$ (fracción oxidable) asistidas por $30 \mathrm{~min}$ en baño de ultrasonido. La fracción residual se determinó por diferencia con la concentración total. 


\section{Análisis estadístico}

Todos los análisis fueron realizados a través del programa R 3.4.1, utilizando los paquetes Vegan y Stats (R Core Team 2018). Para determinar si existen diferencias significativas entre los valores de algunos parámetros $(\mathrm{n}=36)$ se usó la prueba no paramétrica de Wilcoxon.

Con el fin de comparaciones de los parámetros físicos y químicos de $\mathrm{Cu}$ y As entre todos los sitios, se realizaron análisis de agrupamiento mediante distancia euclidiana (Magurran 1988). Las variables se unieron con el método de agrupamiento por ligamento promedio no ponderado (UPGMA) (Legendre y Legendre 2003).

\section{RESULTADOS Y DISCUSIÓN}

\section{Parámetros ambientales}

El cuadro I resume los valores para los estadísticos básicos obtenidos de los parámetros fisicos y químicos en las aguas. Los valores de CE, relativamente altos para ríos $(26 \mathrm{mS} / \mathrm{cm})$, permiten comprobar que las aguas y la laguna son saladas $(10-100 \mathrm{mS} / \mathrm{cm})$. Como era de esperarse, se observa un aumento de la salinidad en la zona de mezcla y un valor habitual de CE del océano Pacífico en las muestras de agua de mar. Las aguas continentales y marinas presentan condiciones de levemente alcalinas a alcalinas, producidas por el equilibrio entre carbonatos y bicarbonatos, aunque contribuyen también en ambientes áridos los contenidos de boratos y silicatos. El intervalo de $\mathrm{pH}$ es de relevancia en varios fenómenos físicos, químicos y biológicos tales como reacciones redox, procesos de sorción y reacciones de solubilización-precipitación de iones en disolución. Bugueño et al. (2014), de acuerdo con los resultados, mostraron un gradiente positivo de salinidad y alcalinización de las aguas desde la parte alta de la cuenca del río Loa hasta la parte baja.

Los potenciales redox, todos negativos y cercanos a $-100 \mathrm{mv}$, indican ambientes reductores, y la concentración promedio de $\mathrm{OD}(5.4 \pm 0.2 \mathrm{mg} / \mathrm{L})$ sustenta la vida en medios acuáticos según la norma chilena 1333 (NCh1333), que sugiere para tales efectos una concentración mayor a $5.0 \mathrm{mg} / \mathrm{L}$ (INN 1978).

Los valores de la relación entre las concentraciones de nitrato/fosfato (N/P) disueltos en las aguas del río y la laguna fueron de 2.0 a 3.0, que se encuentran

CUADRO I. ESTADÍSTICA DESCRIPTIVA DE LOS PARÁMETROS FÍSICOS Y QUÍMICOS DETERMINADOS EN LAS AGUAS NATURALES DE LA DESEMBOCADURA DEL RÍO LOA

\begin{tabular}{|c|c|c|c|c|c|c|c|c|c|}
\hline \multirow[t]{2}{*}{ Ambiente } & \multirow[t]{2}{*}{ Estadístico } & \multirow{2}{*}{$\begin{array}{c}\mathrm{CE} \\
(\mathrm{mS} / \mathrm{cm})\end{array}$} & \multirow{2}{*}{$\begin{array}{l}\mathrm{pH} \\
(\mathrm{U})\end{array}$} & \multirow{2}{*}{$\begin{array}{c}\mathrm{E}_{\mathrm{h}} \\
(\mathrm{mv})\end{array}$} & OD & $\mathrm{N}-\mathrm{NO}_{3}^{-}$ & $\mathrm{P}-\mathrm{PO}_{4}{ }^{-3}$ & As & $\mathrm{Cu}$ \\
\hline & & & & & \multicolumn{5}{|c|}{$(\mathrm{mg} / \mathrm{L})$} \\
\hline \multirow{5}{*}{ Cauce del río } & Mediana & 25.5 & 8.95 & -104 & 5.3 & 1.08 & 0.14 & 1.82 & 0.025 \\
\hline & Promedio & 25.7 & 8.94 & -105 & 5.4 & 1.02 & 0.15 & 1.80 & 0.029 \\
\hline & Desviación & 2.5 & 0.23 & 3 & 0.3 & 0.23 & 0.05 & 0.11 & 0.015 \\
\hline & Mínimo & 22.0 & 8.59 & -109 & 5.0 & 0.56 & 0.08 & 1.56 & 0.010 \\
\hline & Máximo & 29.0 & 9.56 & -102 & 5.9 & 1.26 & 0.23 & 1.98 & 0.050 \\
\hline \multirow{5}{*}{ Laguna } & Mediana & 24.3 & 8.64 & -107 & 5.3 & 0.94 & 0.21 & 1.79 & 0.030 \\
\hline & Promedio & 24.3 & 8.66 & -106 & 5.4 & 0.97 & 0.28 & 1.74 & 0.034 \\
\hline & Desviación & 1.1 & 0.18 & 5 & 0.2 & 0.27 & 0.19 & 0.17 & 0.016 \\
\hline & Mínimo & 22.6 & 8.34 & -116 & 5.2 & 0.52 & 0.10 & 1.52 & 0.010 \\
\hline & Máximo & 26.1 & 9.01 & -98 & 5.7 & 1.42 & 0.56 & 1.98 & 0.060 \\
\hline \multirow{5}{*}{ ZM7 } & Mediana & 37.9 & 8.79 & -98 & 5.1 & 0.43 & 0.21 & 1.12 & 0.040 \\
\hline & Promedio & 38.1 & 8.83 & -98 & 5.2 & 0.45 & 0.20 & 1.13 & 0.033 \\
\hline & Desviación & 1.6 & 0.10 & 1 & 0.3 & 0.06 & 0.04 & 0.03 & 0.021 \\
\hline & Mínimo & 36.7 & 8.76 & -99 & 5.0 & 0.41 & 0.15 & 1.10 & 0.010 \\
\hline & Máximo & 39.8 & 8.95 & -97 & 5.5 & 0.52 & 0.23 & 1.16 & 0.050 \\
\hline \multirow{5}{*}{ Playas } & Mediana & 53.0 & 8.63 & -98 & 5.1 & 0.55 & 0.02 & 0.010 & 0.020 \\
\hline & Promedio & 53.8 & 8.62 & -97 & 5.0 & 0.50 & 0.02 & 0.012 & 0.025 \\
\hline & Desviación & 1.6 & 0.06 & 2 & 0.0 & 0.22 & 0.01 & 0.004 & 0.008 \\
\hline & Mínimo & 52.1 & 8.54 & -100 & 5.0 & 0.12 & 0.01 & 0.010 & 0.020 \\
\hline & Máximo & 56.1 & 8.70 & -94 & 5.1 & 0.89 & 0.04 & 0.021 & 0.040 \\
\hline
\end{tabular}

ZM7: zona de mezcla siete, CE: conductividad eléctrica, $\mathrm{E}_{\mathrm{h}}$ : potencial redox, OD: oxígeno disuelto 
por debajo de la proporción estándar para aguas continentales $(\mathrm{N} / \mathrm{P}=15)$, y en las aguas oceánicas, cuyo valor alcanzó 18 , es cercano al valor reportado para océanos $(\mathrm{N} / \mathrm{P}=16)$ (Sigg et al. 1992). Las concentraciones mayores de fosfato continental pueden atribuirse a lixiviaciones por el terreno que circula el río y también producto de la actividad biológica del lugar. Por su parte, Herrera y Escribano (2006) reportaron para las cercanías de la desembocadura condiciones ambientales y propiedades físicas y químicas de las aguas marinas equivalentes a los resultados obtenidos en este estudio; además, establecen que estos sectores del borde costero del norte de Chile están enriquecidos en nutrientes y son aptos para el buen desarrollo del fitoplancton.

El cuadro II resume los valores para los estadísticos básicos obtenidos de los parámetros físicos y químicos de los sedimentos en estudio. Los valores de $\mathrm{pH}$ cercanos a la neutralidad muestran diferencias significativas $(\mathrm{p}<0.0005)$. El contenido de materia orgánica fácilmente oxidable de los sedimentos continentales no presentó correlación con el pH; sin embargo, la cantidad de materia orgánica en los sedimentos del cauce del río (menor $\mathrm{pH}$ ) son prácticamente el doble que en la laguna. El contenido de materia orgánica es un factor que puede influir en la disponibilidad y movilidad de las especies de metales y metaloides en este compartimiento, debido a la capacidad que posee este componente, según el pH, de interaccionar y adsorber estos elementos.

Las propiedades ácido-básicas de la matriz se ven influenciadas por la presencia de carbonatos; en este sentido, se observan diferencias para el contenido de carbonato de calcio $\left(\mathrm{CaCO}_{3}\right)$ : en el cauce del río se encuentran los mayores contenidos del mineral (15.9$30.5 \%$ ), mientras que en la laguna se presenta una distribución más heterogénea (5.3-22\%) y se verifica una disminución; en cambio, en los sedimentos de las playas no se presenta este mineral (Cuadro II). La mayor concentración en el territorio continental se explica por los largos periodos de elevadas tasas de evaporación a los que se ven expuestos estos ecosistemas, y a que en ambientes muy áridos la calcita es comúnmente uno de los primeros minerales que se precipitan desde cuerpos de agua que se evaporan (Herrera et al. 2009).

CUADRO II. ESTADÍSTICA DESCRIPTIVA DE LOS PARÁMETROS FÍSICOS Y QUÍMICOS DETERMINADOS EN LOS SEDIMENTOS DE LA DESEMBOCADURA DEL RÍO LOA (CON BASE EN PESO SECO)

\begin{tabular}{|c|c|c|c|c|c|c|c|c|c|}
\hline \multirow{2}{*}{ Ambient } & \multirow{2}{*}{ Estadístico } & \multirow{2}{*}{$\begin{array}{c}\mathrm{CE} \\
(\mathrm{mS} / \mathrm{cm})\end{array}$} & \multirow{2}{*}{$\begin{array}{l}\mathrm{pH} \\
(\mathrm{U})\end{array}$} & COFO & $\mathrm{CaCO}_{3}$ & $\mathrm{~N}-\mathrm{NO}_{3}{ }^{-}$ & $\mathrm{P}-\mathrm{PO}_{4}{ }^{-3}$ & As & $\mathrm{Cu}$ \\
\hline & & & & \multicolumn{2}{|c|}{$(\%)$} & \multicolumn{4}{|c|}{$(\mathrm{mg} / \mathrm{kg})$} \\
\hline \multirow{5}{*}{$\begin{array}{l}\text { Cauce } \\
\text { del río }\end{array}$} & Mediana & 14.6 & 7.12 & 4.18 & 24.2 & 11.7 & 1.02 & 647 & 15.2 \\
\hline & Promedio & 14.0 & 7.09 & 4.14 & 23.6 & 10.7 & 1.07 & 654 & 13.7 \\
\hline & Desviación & 2.6 & 0.11 & 1.53 & 5.5 & 4.2 & 0.33 & 59 & 4.0 \\
\hline & Mínimo & 9.0 & 6.89 & 1.59 & 15.9 & 5.69 & 0.59 & 569 & 6.6 \\
\hline & Máximo & 17.0 & 7.26 & 6.10 & 30.5 & 17.5 & 1.65 & 750 & 18.9 \\
\hline \multirow{5}{*}{ Laguna } & Mediana & 7.2 & 7.32 & 2.52 & 14.5 & 3.73 & 0.36 & 651 & 29.1 \\
\hline & Promedio & 7.0 & 7.36 & 2.50 & 14.6 & 3.47 & 0.41 & 648 & 28.4 \\
\hline & Desviación & 0.5 & 0.21 & 0.40 & 6.1 & 0.77 & 0.15 & 100 & 4.1 \\
\hline & Mínimo & 6.2 & 7.05 & 2.00 & 5.3 & 2.35 & 0.23 & 516 & 22.0 \\
\hline & Máximo & 7.6 & 7.60 & 3.26 & 22.0 & 4.51 & 0.66 & 856 & 34.5 \\
\hline \multirow{5}{*}{ ZM7 } & Mediana & 19.6 & 7.29 & 2.78 & 6.5 & 1.38 & 0.26 & 659 & 32.5 \\
\hline & Promedio & 19.6 & 7.36 & 2.64 & 6.4 & 1.73 & 0.36 & 663 & 32.9 \\
\hline & Desviación & 1.9 & 0.17 & 0.70 & 0.5 & 0.72 & 0.20 & 76 & 3.7 \\
\hline & Mínimo & 17.8 & 7.24 & 1.89 & 5.9 & 1.26 & 0.23 & 589 & 29.5 \\
\hline & Máximo & 21.5 & 7.56 & 3.26 & 6.9 & 2.56 & 0.59 & 740 & 36.8 \\
\hline \multirow{5}{*}{ Playas } & Mediana & 4.5 & 7.43 & \multirow[t]{5}{*}{ ND } & \multirow[t]{5}{*}{ ND } & 0.75 & 0.59 & 20 & 6.49 \\
\hline & Promedio & 4.7 & 7.39 & & & 0.74 & 0.64 & 21 & 5.89 \\
\hline & Desviación & 0.8 & 0.14 & & & 0.10 & 0.40 & 1 & 2.57 \\
\hline & Mínimo & 3.6 & 7.18 & & & 0.59 & 0.23 & 19 & 2.23 \\
\hline & Máximo & 6.2 & 7.54 & & & 0.89 & 1.08 & 23 & 8.95 \\
\hline
\end{tabular}

ZM7: zona de mezcla siete, ND: no detectable, CE: conductividad eléctrica, COFO: carbono orgánico fácilmente oxidable 
La concentración de nitrato disponible en los sedimentos muestra un patrón de variación similar al fosfato disponible (Fig. 2) pero no con las concentraciones del COFO. Probablemente, la sedimentación de materia orgánica formada mediante la producción primaria (fitoplancton) en el cuerpo de agua, forma parte del aporte principal de carbono, nitrógeno y fósforo (Sigg et al. 1992). La mayor concentración de fosfato disponible en el sedimento se obtuvo en la laguna $(1.0 \pm 0.1 \mathrm{mg} / \mathrm{kg})$, siendo una fracción del fósforo total susceptible de ser asimilado por las plantas, y se le ha considerado como un índice de fertilidad para las comunidades riparias y estuarinas.

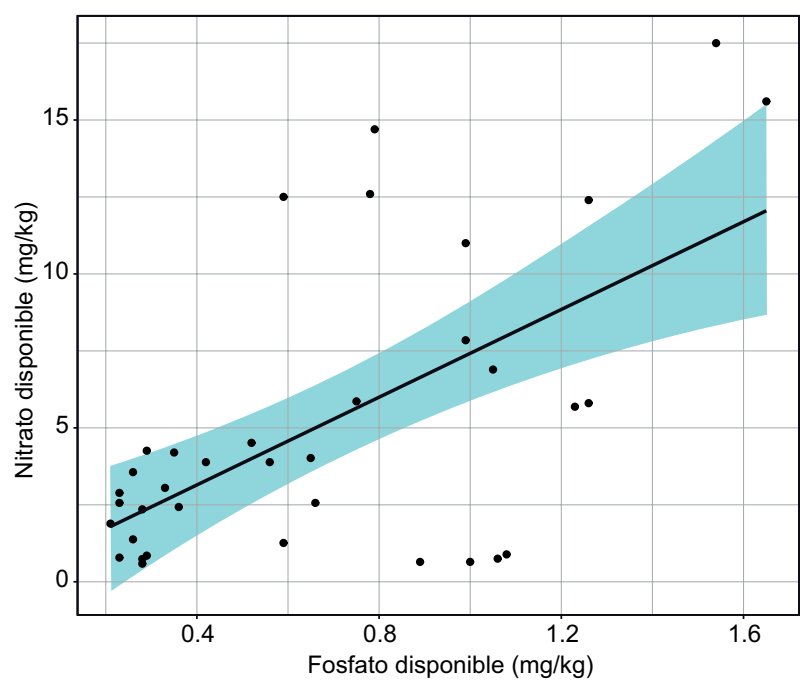

Fig. 2. Relación lineal entre las concentraciones de nitrato y fosfato disponibles en los sedimentos en estudio

El conjunto de resultados permite demostrar que, por su geomorfología y batimetría, el humedal del borde costero se comporta como un sistema acumulador de sales probablemente por evaporación, produciéndose posiblemente la precipitación, coprecipitación y cristalización de una secuencia de minerales con As debido a saturación de éstos en la fase acuosa. La particularidad en los contenidos de $\mathrm{CaCO}_{2}$ permite comparar el efecto de soluciones de ácidos fuertes y un buffer para extraer el As. También es posible que se forme un mineral de fosfato de calcio y se encuentre asociado un precipitado de arseniato (Mandal y Suzuki 2002).

\section{Cobre y arsénico}

La concentración del ion $\mathrm{Cu}$ en las muestras de agua (Cuadro I) es relativamente baja en los cuatro ambientes y no sobrepasa la máxima admisible por la norma NCh1333, que para el metal disuelto establece $0.20 \mathrm{mg} / \mathrm{L}$ (INN 1978). En los sedimentos continentales, las concentraciones de $\mathrm{Cu}$ total muestran valores en un intervalo de 6.58 a $36.8 \mathrm{mg} /$ $\mathrm{kg}$ (Cuadro II). El valor mínimo determinado en la laguna y en los sedimentos del borde costero es cercano al valor promedio en sedimentos de caliza (5.5 $\mathrm{mg} / \mathrm{kg}$ ) señalado por Bowen (1979). Sin embargo, el diagnóstico realizado por Romero et al. (2003) en los sedimentos a lo largo del cauce del río Loa y sus principales tributarios mostró que el intervalo de concentración fue mucho más amplio, entre 50 y $220 \mathrm{mg} / \mathrm{kg}$, adquiriendo valores elevados en áreas de influencia de la actividad minera en Calama y no en la desembocadura. La SQG sugiere una concentración de $\mathrm{Cu}$ en sedimentos según el ERL de $34 \mathrm{mg}$ / $\mathrm{kg}$ y por ERM de $270 \mathrm{mg} / \mathrm{kg}$ (Han et al. 2017), en consecuencia, no existe peligro ambiental potencial en la desembocadura del río Loa por la presencia de este metal.

La concentración de As en las aguas del río y la laguna (Cuadro I) sobrepasan en 18 veces la concentración máxima admisible estipulada para agua destinada a diversos usos por la norma NCh1333 $(0.10 \mathrm{mg} / \mathrm{L})$ y 180 veces la norma chilena y el valor establecido por la Organización Mundial de la Salud (OMS) de $0.01 \mathrm{mg} / \mathrm{L}$ para agua de consumo humano (WHO 2001). Los resultados corresponden con los reportados previamente para la parte baja de la cuenca (Romero et al. 2003, DGA 2005, Pell et al. 2013). En la zona de mezcla se observa una ligera dilución y en las aguas de mar aledañas el As se diluye hasta alcanzar $0.012 \mathrm{mg} / \mathrm{L}$, aunque Bowen (1979), señala una concentración normal en agua de mar de $0.0037 \mathrm{mg} / \mathrm{L}$.

Las concentraciones de As total en los sedimentos continentales de la desembocadura (Cuadro II) alcanzan valores muy elevados $(516-856 \mathrm{mg} / \mathrm{kg})$, mientras que en los sedimentos marinos llegan a 20 $\mathrm{mg} / \mathrm{kg}$. En sedimentos, obtenidos a lo largo del cauce del río Loa, se han reportado concentraciones de 120 y $700 \mathrm{mg} / \mathrm{kg}$, con un valor promedio de $320 \mathrm{mg} / \mathrm{kg}$, y de alrededor de $11000 \mathrm{mg} / \mathrm{kg}$ en sedimentos del sector de la vertiente geotermal El Tatio sobre los $3500 \mathrm{msnm}$ (Romero et al. 2003). Para la parte baja de la cuenca, en la zona del tranque Sloman, Bugueño et al. (2014) determinaron una concentración promedio de $292 \pm 28 \mathrm{mg} / \mathrm{kg}$, pero en el sector de Oasis en Quillagua ésta aumentó a $534 \pm 156 \mathrm{mg} / \mathrm{kg}$. Bowen (1979) señala concentraciones normales para los sedimentos de caliza de $1 \mathrm{mg} / \mathrm{kg}$ y para otros tipos de sedimentos que no superan los $7.7 \mathrm{mg} / \mathrm{kg}$. 
Las arcillas marinas alcanzan valores más altos, en torno a $13 \mathrm{mg} / \mathrm{kg}$. Mandal y Suzuki (2002) señalan que el nivel natural para As en sedimentos es inferior a $10 \mathrm{mg} / \mathrm{kg}$; sin embargo, se puede acumular en sedimentos marinos reductores hasta los $3000 \mathrm{mg} /$ $\mathrm{kg}$. Por su parte, en Latinoamérica, la legislación brasilera sugirió en 2012 una concentración máxima de $19 \mathrm{mg} / \mathrm{kg}$ de As en sedimentos acuáticos (Cagnin et al. 2017).

El potencial efecto ambiental en todo el humedal es relevante, ya que sobrepasa más de 100 veces los valores del ERL $(8.2 \mathrm{mg} / \mathrm{kg})$ y 10 veces lo sugerido por el ERM (70 mg/kg) para As (Han et al. 2017). La presencia del metaloide se ha atribuido a las condiciones del volcanismo, hidrotermalismo (geiser y fumarolas) en la precordillera y altiplano, adquiriendo naturalmente silicio, litio y boro de origen volcánico, lo que se relaciona con un aumento de iones disueltos en sus aguas (Romero et al. 2003, DGA 2005, Pell et al. 2013, Bugueño et al. 2014). También es sabido que la elevada concentración natural es producto del nacimiento del río en la cordillera de los Andes, en las faldas del volcán Miño; asimismo, al aporte hídrico de su tributario el río Salado, que se origina en las vertientes geotermales de El Tatio, las cuales poseen concentraciones de $27 \mathrm{mg} / \mathrm{L}$ (Romero et al. 2003). De igual forma existen descargas antrópicas del elemento traza en áreas de influencia de importantes proyectos mineros de cobre en la zona alta de la cuenca del río Loa (Pell et al. 2013). Los compuestos arsenicales son componentes comunes en los minerales geoquímicos depositados por emanaciones volcánicas y yacimientos metálicos (principalmente arsenopirita), reconocidos como una dificultad natural y antrópica a nivel mundial (Mandal y Suzuki 2002, Liu et al. 2010, Cagnin et al. 2017), y las condiciones áridas y alcalinas han limitado su movilización (Smedley y Kinniburgh 2002).

El cuadro III, resume el promedio de los indicadores ambientales calculados y su desviación. Los valores de $\mathrm{K}_{\mathrm{D}}$ responden al comportamiento general observado en los ecosistemas acuáticos, donde es frecuente encontrar concentraciones en el sedimento superiores a las del agua (Wang et al. 2016). En el río y la laguna se obtuvieron valores similares (364-375), en zona de mezcla aumentan al doble y en el medio marino se incrementa en seis veces. Por su parte, los valores obtenidos para el Igeo clasifican al humedal como ecosistema contaminado ( Igeo $_{\text {ge }} 3-4$ ) pero no a las playas aledañas a la desembocadura; si se calculan los valores con el valor base de As sugerido por el ERL, el humedal está entonces extremadamente contaminado (Han et al. 2017). Los valores del EF, considerando la base geoquímica local de As para el humedal, el ERL para el medio marino y el Cu como normalizador, muestran diferencias significativas ( $\mathrm{p}$ $<0.0005$ ). El sector de mayor depósito del metaloide se observó en el cauce del río, específicamente en la parte de menor pendiente en la quebrada (sitio R2, Fig. 1), lo que se ha atribuido a la disminución de la hidrodinámica en ese sector del río. Por su parte, los sedimentos de la laguna poseen un comportamiento equivalente al cauce del río y un menor grado de enriquecimiento de As. En el medio marino, dado su gran poder de dilución, el EF disminuye considerablemente. Todos los valores relativos obtenidos indican una probabilidad de enriquecimiento antrópico (Wang et al. 2017).

CUADRO III. VALORES PROMEDIO ( \pm DESVIACIÓN ESTÁNDAR) DE LOS INDICADORES AMBIENTALES OBTENIDOS EN LOS CUATRO AMBIENTES DE LA DESEMBOCADURA DEL RÍO LOA

\begin{tabular}{lcccc}
\hline & $\begin{array}{c}\text { Cauce } \\
\text { del río }\end{array}$ & Laguna & $\begin{array}{c}\text { Zona de } \\
\text { mezcla }\end{array}$ & Playas \\
\hline $\mathrm{K}_{\mathrm{D}}(\mathrm{L} / \mathrm{kg})$ & $364 \pm 42$ & $375 \pm 65$ & $633 \pm 108$ & $1835 \pm 367$ \\
$\mathrm{I}_{\mathrm{GEO}}$ & $4.0 \pm 0.1$ & $4.0 \pm 0.2$ & $4.0 \pm 0.2$ & $0.53 \pm 0.05$ \\
$\mathrm{EF}$ & $89 \pm 31$ & $39 \pm 8$ & $39 \pm 11$ & $19 \pm 12$ \\
$\mathrm{RAC}(\%)$ & $38 \pm 2$ & $46 \pm 13$ & $46 \pm 1$ & $50 \pm 2$ \\
\hline
\end{tabular}

$\mathrm{K}_{\mathrm{D}}$ : constante de distribución, $\mathrm{I}_{\mathrm{GEO}}$ : índice de geoacumulación, $\mathrm{EF}$ : factor de enriquecimiento, RAC: código de evaluación de riesgo

Por su parte, los carbonatos más abundantes, caliza $\left(\mathrm{CaCO}_{3}\right)$ y dolomita $\left(\mathrm{MgCO}_{3} \mathrm{CaCO}_{3}\right)$, tienen influencia en el $\mathrm{pH}$ y en la conducta de las especies de As. Los arseniatos se pueden coprecipitar con los carbonatos incorporados en su estructura (Herrera et al. 2009) o bien pueden ser absorbidos tanto por la caliza como por los óxidos de Fe y Mn que pueden estar incluidos dentro de los carbonatos precipitados (Smedley y Kinniburgh 2002). Smedley y Kinniburgh (2002) han señalado también que en los sedimentos acuáticos los principales minerales de As (arsenito y arseniato) están adsorbidos en óxidos de Fe y Mn, lo cual se relaciona con la concentración de As en las aguas, el $\mathrm{pH}$, el $\mathrm{E}_{\mathrm{h}}$, el tipo y textura de la arcilla y la materia orgánica, pero generalmente con altas concentraciones de Fe. La adsorción es mayor en esta fracción (Fang y Chen, 2015). Por los antecedentes expuestos, el As en los sedimentos del humedal se debería a la precipitación o coprecipitación de los 
oxoaniones presentes en las aguas con los carbonatos, y/o a fenómenos de adsorción de As sobre la superficie de oxióxidos de Fe y Mn en la matriz sólida. La presencia de As en sedimentos del fondo se ha atribuido a la presencia de materia orgánica oxidable y su asociación en forma de arseniatos adsorbidos a fosfato de calcio, lo que genera un aumento del riesgo potencial en el ecosistema para especies biológicas que se alimentan con partículas del sedimento.

La figura 3 muestra el análisis de agrupamiento mediante el índice de similitud de distancia euclidiana (Magurran 1988) entre los ambientes definidos, demostrando que las playas aledañas al norte y sur de la desembocadura tienen un comportamiento similar. En cambio, en el cauce del río existe semejanza entre áreas de mayor pendiente y escorrentía (R1 y R3). En la laguna del humedal y la zona de mezcla dicho índice muestra mayor distancia respecto de los otros sitios debido a la cercanía y dinámica propia del sistema fluvial y el oleaje. También podemos observar similitud entre los sitios L4 y L6, pero no con L5, lo cual se atribuye a la morfometría de la laguna, que en el centro posee la mayor profundidad.

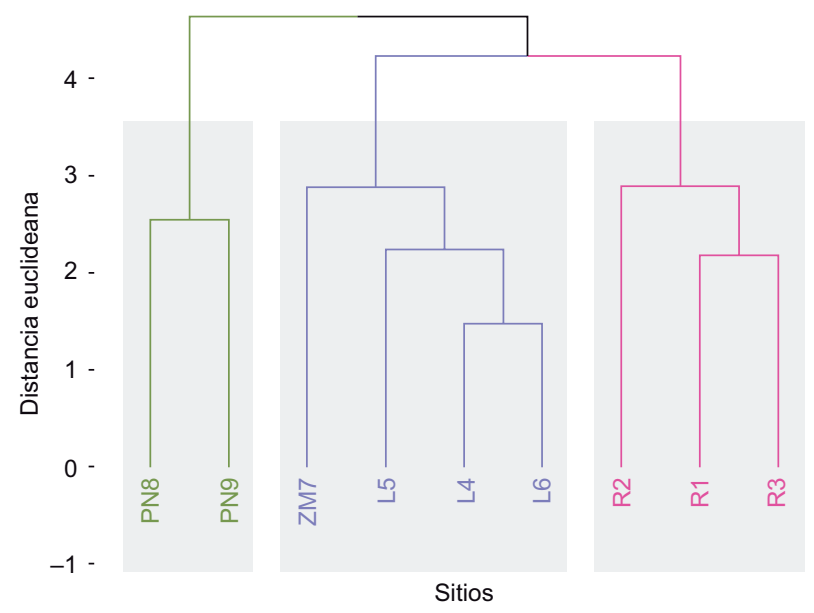

Fig. 3. Dendrograma de conglomerados jerárquicos mediante el método de agrupamiento por ligamento promedio no ponderado (UPGMA) para parámetros físicos y químicos analizados en los sitios muestreados de la desembocadura del río Loa

\section{Extracciones simples y extracciones secuenciales de As}

Los resultados de la efectividad en la extracción simple de As, referida funcional (disponible, biodisponible) u operacionalmente (soluble en medio ácido), manifiestan un riesgo ambiental específico, ya que modifican las propiedades ácido-básicas de los ecosistemas. Así, se obtuvieron de 50 a $74 \%$ de extracción de As desde el medio marino y de 25 a $70 \%$ desde el humedal (Fig. 4). En todos los sitios, la mayor efectividad (la cual fue similar) se obtuvo con ácido sulfúrico $0.25 \mathrm{M}$, pero los porcentajes de extracción con ácido clorhídrico $1 \mathrm{M}$ y amortiguador de acetato también lo ubican como biodisponible para organismos. Es relevante mencionar que ocurre un aumento en los porcentajes de extracción de As con el buffer acetato en los sedimentos de playas, el cual puede atribuirse a su asociación con minerales de fosfato de calcio que pueden ser redisueltos por intercambio iónico. Excepto en los sedimentos marinos, la concentración de As extraída (soluble en ácido) sobrepasa la sugerida por el ERM $(70 \mathrm{mg} / \mathrm{kg})$.

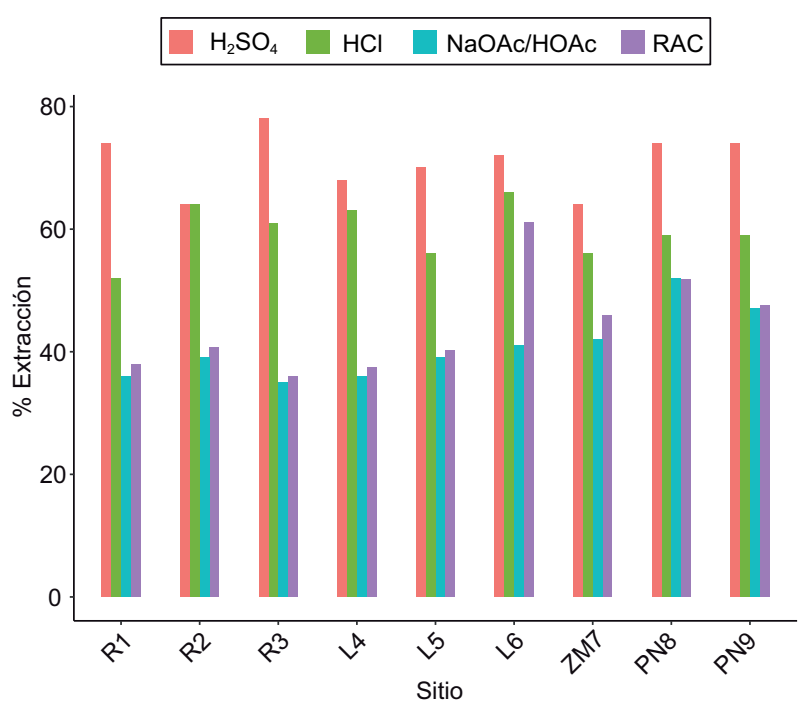

Fig. 4. Porcentajes de extracción de As con amortiguador de acetato, soluciones de ácido clorhídrico y ácido sulfúrico y del RAC (código de evaluación de riesgo) en los sitios del cauce final del río, la laguna, zona de mezcla y playas de los sectores norte y sur de la desembocadura del río Loa

La concentración del As extraído tiene una buena relación lineal positiva con su concentración total en sedimentos (Fig. 5). Este comportamiento era esperable debido a los fenómenos de acumulación del metaloide; en consecuencia, su movilidad desde el sedimento hasta el agua es mayor si el caudal normal disminuye o por un aumento en la tasa de evaporación. Un aumento en la pendiente de las curvas se debe probablemente a la agresividad del reactivo y una destrucción mayor de la matriz. 


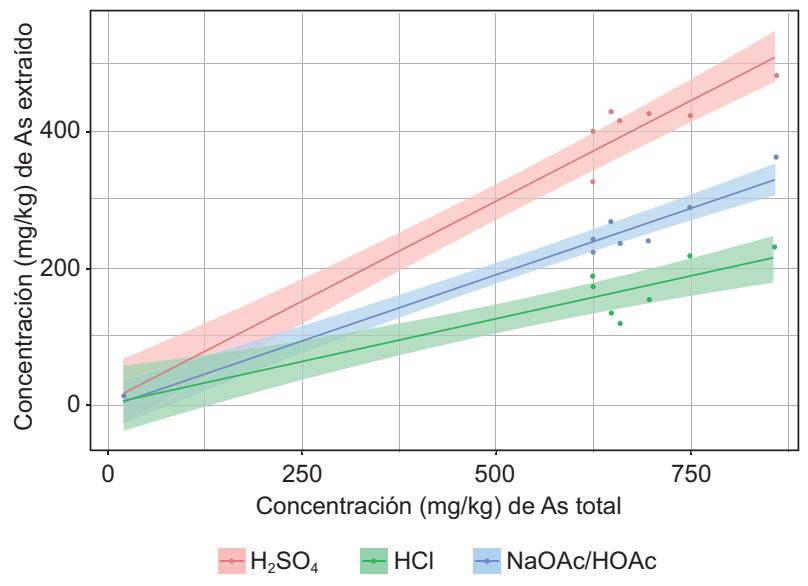

Fig. 5. Relación lineal entre la concentración de As extraído con amortiguador de acetato, soluciones de ácido clorhídrico y ácido sulfúrico, y la concentración total de As en los sedimentos de la desembocadura del río Loa

Los niveles alcanzados para el código de evaluación de riesgo (Cuadro II y Fig. 4) son coincidentes, y establecen que el riesgo en el medio marino (50 $\pm 2 \%$ ) es muy elevado, mientras que en la laguna $(46 \pm 13 \%)$, en la zona de mezcla $(46 \pm 1 \%)$ y en el cauce final del río ( $38 \pm 2 \%$ ) es elevado (Wang et al. 2016). Independientemente de la concentración total de As, los resultados muestran una importante biodisponibilidad de este elemento para los organismos del humedal y el medio marino, cuyos hábitos tróficos dependen de las partículas depositadas en el fondo, que además pueden removilizarse a la columna de agua y elevar el riesgo biológico. El riesgo es potencial basado en una metodología práctica, pero que no considera la realidad en términos de fuerza iónica y actividad protónica.

Los resultados de las concentraciones de As asociado a cada fracción del esquema armonizado por la BCR y modificado, se muestran en un diagrama de caja y bigote en la figura 6. El humedal costero tiene un comportamiento prácticamente similar: As se encuentran equitativamente distribuido entre las fracciones reducible, orgánica e intercambiable, sobrepasando hasta cinco veces el valor del ERM. La concentración obtenida en la fracción intercambiable es la más dañina para los organismos acuáticos (Wang et al. 2016); en cambio, en el borde costero el As se encuentra mayoritariamente en la fase intercambiable y residual, sobrepasando levemente el valor del REL, por lo que su riesgo potencial para el ambiente marino es discutible.

Las variaciones en las propiedades físicas y químicas en el humedal del borde costero, tales como salinidad, $\mathrm{pH}$, potencial redox y materia orgánica

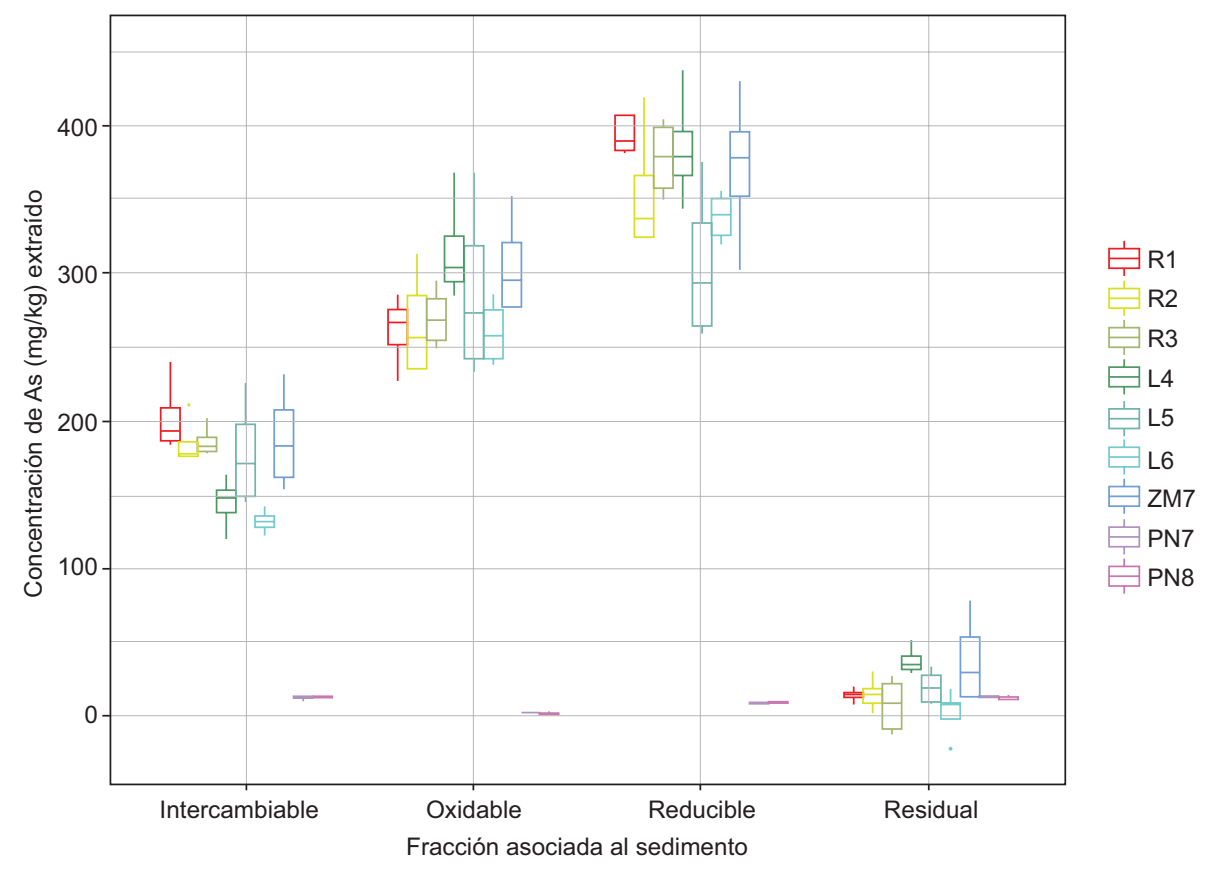

Fig. 6. Diagrama de cajas y bigotes para la concentración de $\mathrm{As}(\mathrm{mg} / \mathrm{kg})$ extraído de la fracción asociada al sedimento (intercambiable, reducible, oxidable y residual) en los sitios del cauce final del río, la laguna, la zona de mezcla y las playas de los sectores norte y sur de la desembocadura del río Loa 
desempeñan un papel importante en el transporte y resuspensión de As en la fase acuosa, los cuales influyen en la acumulación en el sedimento y en el ingreso al mar.

\section{CONCLUSIONES}

En el cauce final del río Loa y la laguna en la plataforma litoral de su desembocadura, las aguas saladas y alcalinas poseen un carácter reductor y contenidos de oxígeno disuelto aceptables para el medio acuático; además, el contenido de nitrato disuelto es limitado de acuerdo con la relación nitrato/ fosfato. Existen niveles normales de $\mathrm{Cu}$ disuelto que no representan un peligro ambiental potencial. La elevada concentración de As $(1.80 \mathrm{mg} / \mathrm{L})$ en las aguas sobrepasa los valores establecidos por la legislación chilena e internacional. El metaloide se diluye en el agua de mar hasta $0.012 \mathrm{mg} / \mathrm{L}$ y la relación nitrato/ fosfato concuerda con los valores establecidos para aguas oceánicas.

Los sedimentos continentales neutros muestran un gradiente longitudinal del contenido de materia orgánica fácilmente oxidable, desde el río hasta la zona de mezcla en la laguna. Hay conductas similares entre las concentraciones de nitrato y fosfato disponibles, e importantes contenidos de carbonato de calcio (alrededor de $15 \%$ ). Las concentraciones de $\mathrm{Cu}$ son normales tanto en los ambientes terrestres como en el mar, pero las de As en los sedimentos del humedal costero son muy elevadas ( $640 \mathrm{a} 800 \mathrm{mg} / \mathrm{kg}$ ) y en los sedimentos de playa alcanzaron $20 \mathrm{mg} / \mathrm{kg}$. Los valores del Igeo de As confirman la categoría de contaminación terrestre, pero no marina; sin embargo, los niveles de los factores de enriquecimiento confirman la extensión de un riesgo ambiental potencial en toda la desembocadura.

Los altos porcentajes de As extraído con las soluciones de ácidos clorhídrico y sulfúrico, y amortiguador de acetato, así como el RAC lo suponen móvil y biodisponible, y se acrecientan conforme la concentración del elemento aumenta. El nivel de As en el sedimento fluvial asociado a con fracciones intercambiable, reducible y oxidable implica elevada movilidad y representa un riesgo para el ecosistema en condiciones de $\mathrm{pH}$ alcalino y reductoras. En cambio, en el borde costero adyacente, As asociado mayoritariamente con la fracción residual e intercambiable implica baja movilidad y se reduce el riesgo potencial.

En general, la capacidad de los agentes extractantes usados dependen de su asociación con las fracciones particulares en la matriz sólida, pero en los sedimentos continentales ocurre la remoción de As por la disolución de los carbonatos o bien arsenitos y arseniatos de calcio, sin descartar la posibilidad de una asociación de arseniatos con fosfatos de calcio.

El curso final del río, la laguna del humedal y las playas aledañas de la desembocadura del río Loa presentan riesgo ecológico potencial por la elevada concentración de As total en los sedimentos y las aguas someras que los cubren, y por su movilidad ante cambios en las condiciones ambientales.

\section{AGRADECIMIENTOS}

Los autores agradecen el financiamiento a la Universidad Arturo Prat del estado de Chile, a su Centro de Investigación del Medio Ambiente CENIMA y al proyecto CONICYT REGIONAL/CIDERH R09I1001.

\section{REFERENCIAS}

APHA. (1992). Métodos normalizados para el análisis de aguas potables y residuales. American Public Health Association-American Water Works Association-Water Pollution Control Federation. Ediciones Díaz de Santos, Madrid, España, 1830 pp.

Arain M.K., Jalbani N., Afridi H. y Baig J. (2008). Speciation of heavy metals in sediment by conventional, ultrasound and microwave assisted single extraction methods: A comparison with modified sequential extraction procedure. J. Hazard. Mater. 154 (1-3), 9981006. DOI: 10.1016/j.jhazmat.2007.11.004

Bowen H. (1979). Environmental chemistry of the elements. Academic Press, Nueva York, Londres, 333 pp.

Bugueño M., Acevedo S., Bonilla C., Pizarro E. y Pasten P. (2014). Differential arsenic binding in the sediments of two sites in Chile's lower Loa River basin. Sci. Total Environ. 466-467, 387-396.

DOI: $10.1016 /$ j.scitotenv.2013.06.114

Bundschuh J., Litter M., Parvez F., Román-Ross G., Nicolli H.B., Jean JS., Liu CW., López D., Armienta M.A., Guillerme LR., Cuevas A.G., Cornejo L., Cumbal L. y Torijáquez R. (2012). One century of arsenic exposure in Latin America: A review of history and occurrence from 14 countries. Sci. Total Environ. 429, 2-35.

DOI: 10.1016/j.scitotenv.2011.06.024

Cagnin R., Quaresma V.S., Chaillou G., Franco T. y Bastos A.C. (2017). Arsenic enrichment in sediment on the Eastern continental shelf of Brazil. Sci. Total Environ. 607-608, 304-316.

DOI: 10.1016/j.scitotenv.2017.06.162 
Chen M., Chen M.L., Ma L. y Chen X. (2014). New procedures for arsenic speciation: A review. Talanta $125,78-86$.

DOI: $10.1016 /$ j.talanta.2014.02.037

DGA (2005). Evaluación de los recursos hídricos superficiales en la cuenca del río Loa. Informe técnico SDT $\mathrm{N}^{\mathrm{o}}$ 192. Dirección General de Aguas, Ministerio de Obras Públicas, Santiago, Chile, 38 pp.

Fang T. y Chen Y. (2015). Arsenic speciation and diffusion flux in Danshuei Estuary sediments, Northern Taiwan. Mar. Pollut. Bull. 101 (1), 98-09.

DOI: 10.1016/j.marpolbul.2015.11.011

Figueroa R., Suárez M.L., Andreu A., Ruiz V.H. y VidalAbarca M.R. (2009). Caracterización ecológica de humedales de la zona semiárida en Chile central. Gayana 73 (1), 76-94.

DOI: $10.4067 / \mathrm{S} 0717-65382009000100011$

Guerra C. (2005). Fauna de vertebrados, flora y vegetación de la desembocadura del río Loa. I y II Región de Chile. Centro Regional de Estudios y Educación Ambiental (CREA). Universidad de Antofagasta, Antofagasta, Chile, 52 pp.

Han D., Cheng J., Hu X., Jiang Z., Mob L., Xua H., Ma Y., Chen X. y Wang H. (2017). Spatial distribution, risk assessment and source identification of heavy metals in sediments of the Yangtze River estuary, China. Mar. Pollut. Bull. 115 (1-2), 141-148.

DOI: 10.1016/j.marpolbul.2016.11.062

Herrera L. y Escribano R. (2006). Factors structuring the phytoplankton community in the upwelling site of El Loa River in northern Chile. J. Marine Systems 61 (12), 13-38. DOI: 10.1016/j.jmarsys.2005.11.010

Herrera V., de Gregori I. y Pinochet H. (2009). Assessment of trace elements and mobility of arsenic and manganese in lagoon sediments of the salars of Huasco and Coposa, Chilean Altiplano. J. Chil. Chem. Soc. 54 (3), 281-288. DOI: 10.4067/S0717-97072009000300017

INN (1978). Norma Chilena Oficial NCh 1333. Of78 Modificada 1987. Requisitos de calidad del agua para diferentes usos. Instituto Nacional de Normalización, Santiago, Chile, 15 pp.

Magurran A.E. (1988). Ecological diversity and its measurement. Princeton University Press, Nueva Jersey, EUA, 179 pp.

Mandal B. y Suzuki K. (2002). Arsenic round the world: A review. Talanta 58 (1), 201-235.

DOI: $10.1016 / \mathrm{S} 0039-9140(02) 00268-0$

Legendre P. y Legendre L. (2003). Numerical ecology. 2nd English ed. Elsevier Science, Amsterdam, Holanda, $870 \mathrm{pp}$.

Lictevout E., Maass C., Córdoba D., Herrera V. y Payano R. (2013). Recursos hídricos región de Tarapacá: Diagnóstico y sistematización de la información. Centro de Investigación y Desarrollo en Recursos Hídricos (CIDERH), Universidad Arturo Prat, Iquique, Chile, $223 \mathrm{pp}$.

Liu J., Chen Y., Wang J., Qi J., Wang Ch., Lippold H. y Lippmann-Pipke J. (2010). Factor analysis and sequential extraction unveil geochemical processes relevant for trace metal distribution in fluvial sediments of pyrite mining area, China. Carbonate. Evaporite. 25 (1), 51-63. DOI: 10.1007/s13146-010-0007-4

Pell A., Márquez A., Fermín J, López-Sánchez J., Rubio R., Barbero M., Stegen S., Queirolo F. y Díaz P. (2013). Occurrence of arsenic species in algae and freshwater plants of an extreme arid region in northern Chile, the Loa River Basin. Chemosphere 90 (2), 556-564.

DOI: 10.1016/j.chemosphere.2012.08.028

R Core Team (2018). R: A language and environment for statistical computing. R Foundation for Statistical Computing, Vienna, Austria [en línea]. https://www.Rproject.org/ 08/01/2018

Romero L., Alonso H., Campano P., Fanfani R., Cidu R., Dadea C., Keegan T. y Farago M. (2003). Arsenic enrichment in waters and sediments of the Rio Loa (Second Region, Chile). Appl. Geochem. 18 (9), 13991416. DOI: $10.1016 / \mathrm{S} 0883-2927(03) 00059-3$

Sadzawka R., Carrasco M., Grez R., Mora M., Flores H. y Neaman A. (2006). Métodos de análisis recomendados para los suelos de Chile. Instituto de Investigaciones Agropecuarias, Santiago, Chile, 164 pp. (Serie Actas 34).

Sielfeld W., Peredo R., Fuentes R., Malinarich V. y Olivares F. (2012). Humedales costeros del norte de Chile. En: Humedales costeros de Chile: aportes científicos a su gestión sustentable (Fariña J.M. y Camaño A., Eds.). Ediciones Universidad Católica, Santiago, Chile, 464 pp.

Sigg L., Behra P. y Stumm W. (1992). Chimie des milieux aquatiques. Chimie des eaux naturalles et des interfaces dans 1' environment. Masson, París, Francia, 564 pp.

Smedley P. y Kinniburgh D. (2002). A review of the source, behavior and distribution of arsenic in natural waters. Appl. Geochem. 17 (5), 517-568.

DOI: 10.1016/S0883-2927(02)00018-5

Tessier A., Campbell P.G. y Bisson M. (1979). Sequential extraction procedure for the speciation of particulate trace metals. Anal. Chem. 51 (7), 844-850.

DOI: 10.1021/ac50043a017

Ure A. M., Quevauviller Ph., Muntau H. y Griepink B. (1993). Speciation of heavy metals in soils and sediments. An account of the improvement and harmonization of extraction techniques undertaken under the auspices of the BCR of the commission of the European Communities. Intern. J. Environ. Anal. Chem. 51, 135151. DOI:10.1080/03067319308027619 
Wang H., Liu R., Wang Q., Xu F., Men C. y Shen Z. (2016). Bioavailability and risk assessment of arsenic in surface sediments of the Yangtze River estuary. Mar. Pollut. Bull. 113 (1-2), 125-131.

DOI: 10.1016/j.marpolbul.2016.08.076
WHO (2001). Arsenic and arsenic compounds. 2nd ed. World Health Organization, Ginebra, Suiza, 114 pp. (Environmental Health Criteria 224). 